\title{
Allyloxy- and Benzyloxy-Substituted Pyridine-bis-imine Iron(II) and Cobalt(II) Complexes for Ethylene Polymerization
}

\author{
Il Kim*, Byeong Heui Han, Jae Sung Kim, and Chang-Sik Ha \\ Department of Polymer Science and Engineering, Pusan National University, Jangjeon, Geumjeong, Busan 609-735, Korea
}

Received May 28, 2004; Revised November 22, 2004

\begin{abstract}
A series of ethylene polymerization catalysts based on tridentate bis-imine ligands coordinated to iron and cobalt was reported. The ligands were prepared through the condensation of sterically bulky anilines with allyloxy- and benzyloxy-substituted 2,6-acetylpyridines. The pre-catalyst complexes were penta-coordinate species of the general formula $\left\{\left[(\mathrm{ArN}=\mathrm{C}(\mathrm{Me}))_{2}\left(4-\mathrm{RO}-\mathrm{C}_{5} \mathrm{H}_{3} \mathrm{~N}\right)\right] \mathrm{MCl}_{2}\right\}(\mathrm{Ar}=$ ortho dialkyl-substituted aryl ring; $\mathrm{R}=$ allyl, benzyl; $\mathrm{M}=\mathrm{Fe}, \mathrm{Co}$ ). In the presence of ethylene and methyl alumoxane cocatalysts, these complexes were active for the polymerization of ethylene, with activities lower than those of metal complexes of the general formula $\{[(2-\mathrm{ArN}=$ $\left.\mathrm{C}(\mathrm{Me}))_{2} \mathrm{C}_{5} \mathrm{H}_{3} \mathrm{~N}\right] \mathrm{MCl}_{2}$ \} ( $\mathrm{Ar}=$ ortho dialkyl-substituted aryl ring; $\left.\mathrm{M}=\mathrm{Co}, \mathrm{Fe}\right)$, containing no substituents in 2,6acetylpyridine ring. The effects of the catalyst structure and temperature on the polymerization activity, thermal properties, and molecular weight were discussed.
\end{abstract}

Keywords: catalysis, electronic effects, polyethylene, polymerization, transition metal chemistry.

\section{Introduction}

A new series of iron and cobalt complexes with bis (imino)pyridyl ligands were reported by Gibson, ${ }^{1}$ Bennett from Dupont ${ }^{2}$ and Brookhart, ${ }^{3,4}$ which showed exceptionally high activity for the ethylene polymerization. Bulky bis (imino)pyridyl ligands have drawn considerable interest because they showed the potential advantages of modulating steric and electronic properties by varying the amine or aniline used in the ligand synthesis. Brookhart group reported that by reducing the steric bulk of these bis(imino)pyridyl ligands the resultant iron catalysts were effective rather oligomerization of ethylene to linear $\alpha$-olefins with remarkably high activity and selectivity while maintaining desirable oligomer distributions. ${ }^{5}$

The elucidation of ligand effects has been a central piece of work in olefin polymerizations over homogeneous catalysts, both metallocene and post-metallocene catalysts, as the catalytic activity and the polymer parameters such as molecular weight (MW) and molecular weight distribution (MWD) can be tailored through a rational ligand design at the transition metal center. Most investigations into ligand effects in such polymerizations have focused on the influence of the steric environment $^{6-9}$ and comparatively few have addressed the question how electronic changes in a ligand affect the metal

*e-mail: ilkim@pnu.edu

1598-5032/02/2-06@2005 Polymer Society of Korea center and its catalytic properties. ${ }^{10-13}$ Electronic together with steric effects have at times been invoked to explain the influence of different cyclopentadienyl ligand substituents in metallocene complexes, e.g. by Ewen et al. ${ }^{14}$ Chien and Razavi $^{15}$ and Mise et al. ${ }^{16}$ No definitive proof for an electronic effect could be given in these articles, however, since the complexes simultaneously differed in their steric hindrance.

To single out the steric from the electronic effects, Piccolrovazzi et al. employed unbridged indenyl ligands carrying a hydrogen, methyl, methoxy or fluorine ligand in the 4and 7-position (on the annelated six-membered ring). ${ }^{10} \mathrm{~A}$ similar approach was taken by Lee et $a l$. who used bridged and unbridged indenyl ligands on a zirconium center which were similarly substituted at the 4- and 7- or 5- and 6-positions. ${ }^{11}$ Substituents on the $\mathrm{C}_{6}$ fragment of these bis(indenyl) zirconium complexes were assumed not to interfere sterically with the incoming monomer, the growing polymer chain or with the insertion reaction at the transition metal center. As a result it was proposed that electron withdrawing groups led to a decrease in catalytic activity and polymer molar mass in the polymerization of ethylene and propylene, while the effect of electron donors was less clear. ${ }^{6(\mathrm{~m}), 11}$

Even though much interest has been drawn on the effect of the protective bulk of the ortho substituents above and below the metal center of pyridine-bis-imine iron(II) and cobalt(II) complexes on the ethylene polymerization behaviors, no results on the effect of substituents on the pyridine (backbone) ring on the polymerization have been reported. 
In this sense we decided to study the synthesis of iron(II) and cobalt(II) complexes with bis(imino)pyridyl ligands containing electron donating benzyloxy and allyloxy substituents on the 2,6-acetylpyridine and the effect of these substituents on the ethylene polymerization behaviors.

\section{Experimental}

General Methods and Materials. Iron and cobalt complexes were manipulated by standard schlenk techniques. Polymerization grade of ethylene (SK, Korea) was purified by passing it through columns of Fisher RIDOX catalyst and molecular sieve $5 \AA / 13 X$. Organic solvents were distilled from $\mathrm{Na} /$ benzophenone and stored over molecular sieves (4 $\AA$ ). All reagents were purchased from Aldrich Chemical Co. and used without purification. Methylaluminoxane (MAO) was purchased from Akzo Chemical as $8.4 \mathrm{wt} \%$ total $\mathrm{Al}$ solution in toluene.

Polymerization and Characterization. Ethylene polymerizations were performed in a $250 \mathrm{~mL}$ round-bottom flask equipped with a magnetic stirrer and a thermometer. Detailed polymerization and polymer workup procedures were described elsewhere. ${ }^{17}$

${ }^{1} \mathrm{H}$ and ${ }^{13} \mathrm{C}$-NMR spectra were recorded on a Varian Gemimi 2000 \& HP5P (300 MHz). All chemical shifts were reported in parts per million $(\delta)$ relative to tetramethylsilane. Thermal analysis of polyethylene was carried out by using differential scanning calorimeter (DSC, Perkin-Elmer Pyris 1) at $10^{\circ} \mathrm{C} / \mathrm{min}$ heating rate under nitrogen atmosphere. The results of the second scan are reported to eliminate difference in sample history. Elementary analysis was carried out using Vario EL. The intrinsic viscosity was measured in decalin at $135^{\circ} \mathrm{C}$ using an Ubbelohde viscometer and the average of molecular weight was calculated by following relation, $[\eta]=6.2 \times 10^{-4} M_{v}^{0.7}{ }^{0.18}$

4-(Allyloxy)-2,6-diacetylpyridine. 4-(Allyloxy)-2,6-diacetylpyridine was prepared by reacting 4-(allyloxy)-2,6-pyridinedicarboxylic acid with thionyl chloride, and then with methyl lithium in the presence of $\mathrm{CuI}(\mathrm{I})$ catalyst according to the reported procedures. ${ }^{17}$

Diethyl 4-(benzyloxy)-2,6-pyridinedicarboxylate. To a stirred solution of $11.96 \mathrm{~g}(50.0 \mathrm{mmol})$ of diethyl 4-hydroxy2,6-pyridinedicarboxylate ${ }^{17}$ and $13.82 \mathrm{~g}(100.0 \mathrm{mmol})$ of $\mathrm{K}_{2} \mathrm{CO}_{3}$ in $100 \mathrm{~mL}$ of acetone at room temperature under argon was stirred for $1 \mathrm{~h}$, and then $34.2 \mathrm{~g}(200.0 \mathrm{mmol})$ of benzyl bromide was added. The reaction mixture was refluxed for $15 \mathrm{~h}$ at $80^{\circ} \mathrm{C}$, diluted with $300 \mathrm{~mL}$ of ethyl acetate and washed with $100 \mathrm{~mL}$ of water. The organic layer was dried over $\mathrm{MgSO}_{4}$ and concentrated under reduced pressure. The residue was purified by flash chromatography $\left(\mathrm{SiO}_{2}, \mathrm{EtOAc-}\right.$ Hexane $=1: 2$ ) to give a product as a yellow solid $13.8 \mathrm{~g}$ (yield $=83 \%) .{ }^{1} \mathrm{H}-\mathrm{NMR}\left(300 \mathrm{MHz}, \mathrm{CDCl}_{3}\right) 1.38(\mathrm{t}, 6 \mathrm{H}$, $J=6.9 \mathrm{~Hz}), 4.38$ (q, $4 \mathrm{H}, J=6.9 \mathrm{~Hz}), 5.15(\mathrm{~s}, 2 \mathrm{H}), 7.32(\mathrm{t}$, $1 \mathrm{H}, J=2.7), 7.36$ (d, 2H, J=1.8), 7.37 (d, 2H, J=1.2), 7.80 (s, 2H). ${ }^{13} \mathrm{C}-\mathrm{NMR}\left(75 \mathrm{MHz}, \mathrm{CDCl}_{3}\right)$ 13.1, 61.4, 69.7, 113.6, 126.7, 127.7, 127.8, 138.6, 149.1, 163.6, 165.5. Anal. Calcd for $\mathrm{C}_{18} \mathrm{H}_{19} \mathrm{NO}_{5}: \mathrm{C}, 65.64 ; \mathrm{H}, 5.81 ; \mathrm{N}, 4.25$. Found: $\mathrm{C}, 65.52$; H, $5.71 ; \mathrm{N}, 4.24$.

4-(Benzyloxy)-2,6-pyridinedicarboxylic acid. To a stirred solution of $11.48 \mathrm{~g}$ ( $35.0 \mathrm{mmol})$ of diethyl 4-(benzoyloxy)2,6-pyridinedicarboxylate in $60 \mathrm{~mL}$ of THF and $20 \mathrm{~mL}$ of a $4 \mathrm{~N} \mathrm{NaOH}$ solution was heated at $50^{\circ} \mathrm{C}$ for $4 \mathrm{~h}$. The reaction mixture was cooled in an ice-water bath and acidified with a $4 \mathrm{~N} \mathrm{HCl}$ solution. The organic layer was separated, washed with water, dried over $\mathrm{MgSO}_{4}$, and concentrated under reduced pressure. The residue was purified by recrystallization from diethyl ether in $\mathrm{MeOH}$ in to afford $6.7 \mathrm{~g}(70 \%)$ as a yellow powder. ${ }^{1} \mathrm{H}-\mathrm{NMR}\left(300 \mathrm{MHz}, \mathrm{DMSO}-d_{6}\right) 5.37$ (s, $2 \mathrm{H}), 7.40(\mathrm{t}, 1 \mathrm{H}, J=5.1 \mathrm{~Hz}), 7.48(\mathrm{~d}, 2 \mathrm{H}, J=8.4 \mathrm{~Hz}), 7.50$ (d, 2H, $J=6.6 \mathrm{~Hz}), 7.80 \quad(\mathrm{~s}, 2 \mathrm{H}) .{ }^{13} \mathrm{C}-\mathrm{NMR} \quad(75 \mathrm{MHz}$, DMSO- $d_{6}$ ) 70.0, 113.8, 127.7, 128.1, 128.4, 135.4, 149.6, 165.1, 166.3. Anal. Calcd for $\mathrm{C}_{14} \mathrm{H}_{11} \mathrm{NO}_{5}$ : C, 61.54; $\mathrm{H}, 4.06$; N, 5.13. Found: C, 61.52; H, 4.11; N, 5.14.

4-(Benzyloxy)-2,6-diacetylpyridine. $6.0 \mathrm{~g}(22.0 \mathrm{mmol})$ of 4-(benzyloxy)-2,6-pyridinedicarboxylic acid was dissolved in $19.1 \mathrm{~mL}(220.0 \mathrm{mmol})$ of thionyl chloride with catalytic amount of DMF and heated to be refluxed overnight until it became a clear solution. The excess of thionyl chloride was removed under reduced pressure. The resulting solid was ground to power and dried under vacuum. Methyl lithium in ether $(30 \mathrm{~mL}, 42.60 \mathrm{mmol}$ ) was added over $1 \mathrm{~h}$ into the suspension of $8.11 \mathrm{~g}(43.60 \mathrm{mmol})$ of $\mathrm{CuI}(\mathrm{I})$ in $40 \mathrm{~mL}$ of ether and $60 \mathrm{~mL}$ of THF at $78^{\circ} \mathrm{C}$. The resulting yellow suspension was slowly warmed up to $-20^{\circ} \mathrm{C}$ over $1 \mathrm{~h}$, then cooled to $78^{\circ} \mathrm{C}$ again. The crude acid chloride compound $(4.77 \mathrm{~g}$, $15.38 \mathrm{mmol}$ ) in $30 \mathrm{~mL}$ of THF was added over $30 \mathrm{~min}$. The resulting orange-yellow suspension was stirred at temperature lower than $-30^{\circ} \mathrm{C}$ for $2.5 \mathrm{~h}$ and then hydrolyzed with saturated $\mathrm{NH}_{4} \mathrm{Cl}$ solution. The mixture was filtered through Celite, and washed consecutively with ether and $\mathrm{CH}_{2} \mathrm{Cl}_{2}$. The combined organic solutions were dried over $\mathrm{MgSO}_{4}$, and then filtered. After removal of solvents, the residue was purified by flash chromatography to give $1.89 \mathrm{~g}(42 \%)$ of desired product as a yellow powder $\left(\mathrm{SiO}_{2}\right.$, EtOAc-Hexane $=$ 1:10). ${ }^{1} \mathrm{H}-\mathrm{NMR}\left(300 \mathrm{MHz}, \mathrm{CDCl}_{3}\right) 2.65$ (s, $\left.6 \mathrm{H}\right), 5.09$ (s, 2 H), $7.27(\mathrm{t}, 1 \mathrm{H}, J=2.7 \mathrm{~Hz}), 7.30(\mathrm{~d}, 2 \mathrm{H}, J=4.2 \mathrm{~Hz}), 7.31$ (d, $2 \mathrm{H}, J=4.2 \mathrm{~Hz}), 7.66$ (s, $2 \mathrm{H}) .{ }^{13} \mathrm{C}-\mathrm{NMR}\left(75 \mathrm{MHz}, \mathrm{CDCl}_{3}\right.$ ) 25.4, 70.2, 110.9, 127.3, 128.3, 128.5, 134.7, 154.4, 166.3, 199.1. Anal. Calcd for $\mathrm{C}_{16} \mathrm{H}_{15} \mathrm{NO}_{3}$ : C, 71.36; H, 5.61; N, 5.20. Found: C, 71.42; H, 5.66; N, 5.23.

$N$-((E)-1-\{4-(Allyloxy)-6-[(1E)- $N$-(2,6-dimethylphenyl) ethanimidoyl]-2-pyridinyl\}-ethylidene)-2,6-dimethylaniline (allyl-Me). Literature procedures were employed to synthesize allyl-Me ligand. ${ }^{17}$

$N-((E)-1-\{4-(A l l y l o x y)-6-[(1 E)-N-(2,6-d i m e t h y l p h e n y l)$ ethanimidoyl]-2-pyridinyl\}-ethylidene)-2,6-diisopropylaniline (allyl-iPr). To a stirred solution of $2.44 \mathrm{~g} \mathrm{(11.13} \mathrm{mmol)}$ of 4-(allyloxy)-2,6-diacetylpyridine in $30 \mathrm{~mL}$ of absolute 
ethanol was added $3.95 \mathrm{~g}$ (22.26 mmol) of 2,6-diisopropylaniline. After the addition of a few drops of glacial acetic acid, the solution was refluxed overnight. Upon cooling to room temperature, the product crystallized from ethanol. After filtration the yellow solid was washed with cold ethanol and dried in a vacuum oven at $50{ }^{\circ} \mathrm{C}$ overnight to give $3.77 \mathrm{~g}(58 \%)$ of desired product as a white powder. ${ }^{1} \mathrm{H}$ NMR $\left(300 \mathrm{MHz}, \mathrm{CDCl}_{3}\right) 1.28$ (d, $\left.24 \mathrm{H}, J=6.9 \mathrm{~Hz}\right), 2.36$ (s, $6 \mathrm{H}), 2.87$ (sep, $2 \mathrm{H}, J=6.9 \mathrm{~Hz}), 4.88(\mathrm{~d}, 2 \mathrm{H}, J=5.4 \mathrm{~Hz}$ ), $5.48(\mathrm{~d}, 1 \mathrm{H}, J=10.2 \mathrm{~Hz}), 5.58(\mathrm{~d}, 1 \mathrm{H}, J=17.4 \mathrm{~Hz}), 6.136 .22$ $(\mathrm{m}, 1 \mathrm{H}), 7.22(\mathrm{t}, 2 \mathrm{H}, J=6.0 \mathrm{~Hz}), 7.27(\mathrm{~d}, 4 \mathrm{H}, \mathrm{J}=6.6 \mathrm{~Hz})$, 8.17 (s, $2 \mathrm{H}) .{ }^{13} \mathrm{C}-\mathrm{NMR}\left(75 \mathrm{MHz}, \mathrm{CDCl}_{3}\right)$ 17.44, 23.32, 28.36, 69.08, 108.7, 118.8, 123.0, 123.6, 132.1, 135.8, 146.4, 156.9, 165.7, 166.8. Anal. Calcd for $\mathrm{C}_{36} \mathrm{H}_{47} \mathrm{~N}_{3} \mathrm{O}$ : C, 80.40; H, 8.81; N, 7.81. Found: C, 80.47; H, 8.86; N, 7.78.

$N$-((E)-1-\{4-(Benzyloxy)-6-[(1E)- $N$-(2,6-dimethylphenyl) ethanimidoyl]-2-pyridinyl\}-ethylidene)-2,6-diisopropylaniline (bz-iPr). The bz-iPr ligand was prepared by the similar procedure with allyl-iPr except for using 4-(benzyloxy)2,6-diacetylpyridine. The resulting product was a yellow solid (yield=65\%). ${ }^{1} \mathrm{H}-\mathrm{NMR}\left(300 \mathrm{MHz}, \mathrm{CDCl}_{3}\right) 1.10$ (d, 24 $\mathrm{H}, J=6.6 \mathrm{~Hz}$ ), 2.17 (s, $6 \mathrm{H}), 2.68$ (sep, $2 \mathrm{H}, J=6.9 \mathrm{~Hz}), 5.22$ (s, $2 \mathrm{H}), 7.03(\mathrm{t}, 1 \mathrm{H}, J=2.7 \mathrm{~Hz}), 7.09(\mathrm{~d}, 2 \mathrm{H}, J=7.8 \mathrm{~Hz})$, $7.11(\mathrm{~d}, 2 \mathrm{H}, J=6.3 \mathrm{~Hz}), 7.31(\mathrm{t}, 2 \mathrm{H}, J=7.5 \mathrm{~Hz}), 7.32(\mathrm{~d}, 4 \mathrm{H}$, $\mathrm{J}=6.9 \mathrm{~Hz}), 8.05$ (s, $2 \mathrm{H}) .{ }^{13} \mathrm{C}-\mathrm{NMR}\left(75 \mathrm{MHz}, \mathrm{CDCl}_{3}\right) 17.64$, 23.01, 28.04, 69.98, 108.7, 122.7, 123.4, 127.5, 128.0, 128.4, 135.6, 145.9, 156.5, 165.5, 166.7, 176.3. Anal. Calcd for $\mathrm{C}_{40} \mathrm{H}_{49} \mathrm{~N}_{3} \mathrm{O}$ : C, 81.73; H, 8.40; N, 7.15. Found: C, 81.66; H, 8.46; N, 7.21.

Synthesis of Catalyst Precursors. ${ }^{2,3}$ The ligand (1.1 eq.) and the metal salt $\left(\mathrm{CoCl}_{2}\right.$ or $\left.\mathrm{FeCl}_{2}\right)$ in its hydrated form were added together in a schlenk flask under nitrogen. Stirring was begun and continued for $4 \mathrm{~h}$. Diethylether was added to the reaction to precipitate the complex, and the resultant solids were filtered in air and washed with ether and pentane and dried in vacuo. All of the complexes were prepared in quantitative yields in this manner.

$[N$-( $(E)-1-\{4-($ Allyloxy)-6-[(1E)- $N$-(2,6-dimethylphenyl) ethanimidoyl]-2-pyridinyl\}-ethylidene)-2,6-dimethylaniline] iron(II) chloride (allyl-Me-Fe). Isolated as a dark blue powder. Anal. Calcd for $\mathrm{C}_{28} \mathrm{H}_{31} \mathrm{Cl}_{2} \mathrm{FeN}_{3} \mathrm{O}$ : C, 60.89; H, 5.66; N, 7.61. Found: C, 60.66; H, 5.46; N, 7.62.

[N-((E)-1-\{4-(Allyloxy)-6-[(1E)- $N$-(2,6-dimethylphenyl) ethanimidoyl]-2-pyridinyl\}-ethylidene)-2,6-dimethylaniline] cobalt(II) chloride (allyl-Me-Co). Isolated as a bright green powder. Anal. Calcd for $\mathrm{C}_{28} \mathrm{H}_{31} \mathrm{Cl}_{2} \mathrm{CoN}_{3} \mathrm{O}: \mathrm{C}, 60.55 ; \mathrm{H}, 5.63$; N, 7.57. Found: C, 60.32; H, 5.44; N, 7.64.

[N-((E)-1-\{4-(Allyloxy)-6-[(1E)-N-(2,6-dimethylphenyl) ethanimidoyl]-2-pyridinyl\}-ethylidene)-2,6-diisopropylaniline] iron(II) chloride (allyl-iPr-Fe). Isolated as a blue powder. Anal. Calcd for $\mathrm{C}_{36} \mathrm{H}_{47} \mathrm{Cl}_{2} \mathrm{FeN}_{3} \mathrm{O}: \mathrm{C}, 65.07 ; \mathrm{H}, 7.13$; $\mathrm{N}, 6.32$. Found: C, 65.23; H, 7.24; N, 6.34.

[ $N$-((E)-1-\{4-(Allyloxy)-6-[(1E)- $N$-(2,6-dimethylphenyl) ethanimidoyl]-2-pyridinyl\}-ethylidene)-2,6-diisopropyl- aniline] cobalt(II) chloride (allyl-iPr-Co). Isolated as a gold powder. Anal. Calcd for $\mathrm{C}_{36} \mathrm{H}_{47} \mathrm{Cl}_{2} \mathrm{CoN}_{3} \mathrm{O}$ : C, 64.77; $\mathrm{H}$, 7.10; N, 6.29. Found: C, 65.02; H, 7.14; N, 6.24.

[N-((E)-1-\{4-(Benzyloxy)-6-[(1E)- $N$-(2,6-dimethylphenyl) ethanimidoyl]-2-pyridinyl\}ethylidene)-2,6-isopropylaniline] iron(II) chloride (bz-iPr-Fe). Isolated as a brown powder. Anal. Calcd for $\mathrm{C}_{40} \mathrm{H}_{49} \mathrm{Cl}_{2} \mathrm{FeN}_{3} \mathrm{O}$ : C, 67.23; H, 6.91; N, 5.88. Found: C, 67.45; H, 7.10; N, 5.82.

[N-((E)-1-\{4-(Benzyloxy)-6-[(1E)- $N$-(2,6-dimethylphenyl) ethanimidoyl]-2-pyridinyl\}ethylidene)-2,6-isopropylaniline] cobalt(II) chloride (bz-iPr-Co). Isolated as a dark green powder. Anal. Calcd for $\mathrm{C}_{40} \mathrm{H}_{49} \mathrm{Cl}_{2} \mathrm{CoN}_{3} \mathrm{O}$ : C, 66.94; $\mathrm{H}, 6.88$; N, 5.86. Found: C, 67.14; H, 6.96; N, 5.83.

\section{Results and Discussion}

The pre-catalyst complexes are penta-coordinate species of the general formula $\left\{\left[(\mathrm{ArN}=\mathrm{C}(\mathrm{Me}))_{2}\left(4-\mathrm{RO}-\mathrm{C}_{5} \mathrm{H}_{3} \mathrm{~N}\right)\right] \mathrm{MCl}_{2}\right\}$ (Ar=ortho dialkyl-substituted aryl ring, $\mathrm{R}=$ allyl or benzyl, $\mathrm{M}=\mathrm{Fe}$ or $\mathrm{Co}$ ), consisting of a 4-allyloxy- or 4-benzyloxypyridine-bisimine ligand coordinated to iron(II) and cobalt(II) chloride. The synthetic procedures of complexes are summarized in Scheme I. The iron and cobalt complexes were prepared by the reported procedures; namely, the addition of a slight excess of the ligand to the hydrated or anhydrous form of the iron and cobalt salts in $\mathrm{THF}^{2,3}$ The reactions are complete in all cases in less than two hours, and the products are isolated by filtration or evaporation and washed with ether and pentane to generate the pre-catalysts in near quantitative yields.

Semi-batch polymerizations of ethylene using cobalt and

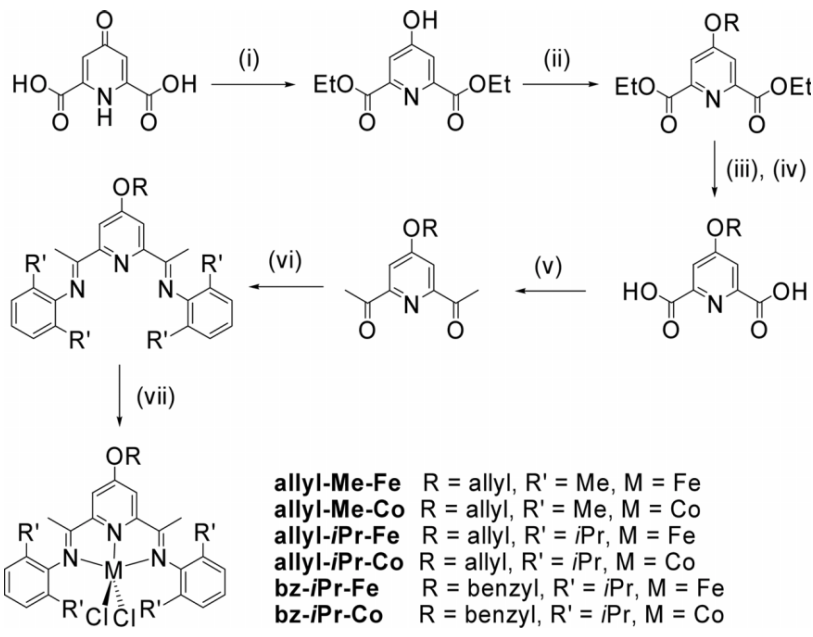

Scheme I. The synthetic route of modified 2,6-bis(imino)pyridyl $\mathrm{Fe}$ (II) and $\mathrm{Co}$ (II) complexes: (i) EtOH, conc. $\mathrm{H}_{2} \mathrm{SO}_{4}, 90^{\circ} \mathrm{C}$; (ii) $\mathrm{K}_{2} \mathrm{CO}_{3}$, allyl bromide or benzyl bromide, acetone, reflux; (iii) $5 \mathrm{~N}-\mathrm{NaOH}, \mathrm{THF}, 50^{\circ} \mathrm{C}$; (iv) $\mathrm{SOCl}_{2}, \mathrm{DMF}, 90^{\circ} \mathrm{C}$; (v) $\mathrm{CuI}(\mathrm{I})$, $\mathrm{MeLi}, \mathrm{Et}_{2} \mathrm{O}$, THF, $-78^{\circ} \mathrm{C}$; (vi) 2,6-dimethylaniline or 2,6-diisopropylaniline, $\mathrm{EtOH}, \mathrm{AcOH}$, reflux; (vii) $\mathrm{FeCl}_{2}$ or $\mathrm{CoCl}_{2}$, THF, r.t. 
iron complexes as catalysts were carried out in the presence of $\mathrm{MAO}$ at a temperature range between 10 and $50{ }^{\circ} \mathrm{C}$. For the comparison $\left\{\left[(\mathrm{ArN}=\mathrm{C}(\mathrm{Me}))_{2} \mathrm{C}_{5} \mathrm{H}_{3} \mathrm{~N}\right] \mathrm{MCl}_{2}\right\} \quad[\mathrm{Ar}=2,6-$ $\left.\mathrm{C}_{6} \mathrm{H}_{3}(i \mathrm{Pr})_{2} ; \mathrm{M}=\mathrm{Fe}(\mathbf{H}-\boldsymbol{i P r}-\mathbf{F e}), \mathrm{Co}(\mathbf{H}-i \mathbf{P r}-\mathbf{C o})\right]$ compounds which have no substituents on the pyridine ring were also utilized for the polymerization at the similar conditions. Figure 1 shows polymerization rate $\left(R_{p}\right)$ profiles obtained at $30^{\circ} \mathrm{C}$ for a demonstration and all polymerization results are summarized in Table I. The ethylene polymerization results demonstrated that (1) for metal complexes containing ligands with the same 2,6-diisoproyl substituted aryl rings, activity decreased in order of $\mathbf{H}-\mathbf{i P r}-\mathbf{M}(\mathbf{M}=\mathrm{Co}, \mathrm{Fe})>$ allyl-iPr-M $>$ bz-iPr-M; (2) even if iron catalyst showed higher activity than cobalt catalyst for $\mathbf{H}-\boldsymbol{i} \mathbf{P r}-\mathbf{M}$ catalysts, the reverse was true for allyl-iPr-M and bz-iPr-M catalysts; (3) there were quite extended induction periods for allyl-iPr-Fe and bz$i$ Pr-Fe catalysts; (4) iron catalysts produced higher molecular weight polymer than cobalt catalysts without exception; (5) metal complexes containing ligands with 2,6-diisoproyl substituted aryl rings yielded higher molecular weight polymer than those with 2,6-dimethyl substituted aryl rings; (6) bz-iPr-Fe catalyst gave much higher molecular weight

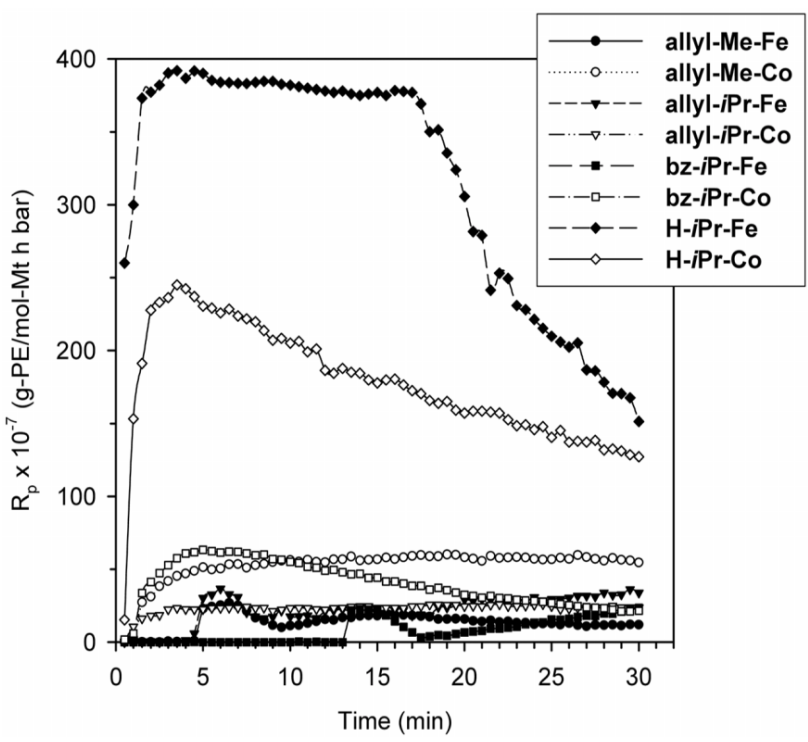

Figure 1. $R_{p}$ versus time of ethylene polymerization catalyzed by pyridyl bis-imine iron and cobalt catalysts in the presence of MAO. Amount of metal used in Table I, toluene $=80 \mathrm{~mL}, \mathrm{PC}_{2} \mathrm{H}_{4}$ $=1.3 \mathrm{bar}, T_{p}=30^{\circ} \mathrm{C}$, and $[\mathrm{Al}] /[\mathrm{Mt}]=700(\mathrm{Mt}=\mathrm{Fe}$ or $\mathrm{Co})$.

Table I. Results of Ethylene Polymerizations over a Series of Pyridyl Bis-imine Iron and Cobalt Catalysts. Polymerization Conditions: Toluene=80 mL, Time=30 min, Ethylene Pressure=1.3 bar, $[\mathrm{MAO}] /[\mathrm{Mt}]=700(\mathrm{Mt}=\mathrm{Fe}$ or $\mathrm{Co})$

\begin{tabular}{|c|c|c|c|c|c|c|c|c|}
\hline Run No. & Catalyst & Loading $(\mu \mathrm{mol})$ & Temp. $\left({ }^{\circ} \mathrm{C}\right)$ & $R_{p, a v g}{ }^{a} \times 10^{-7}$ & $M_{v}^{b} \times 10^{-3}$ & $T_{m}^{c}\left({ }^{\circ} \mathrm{C}\right)$ & $\Delta H_{f}^{c}(\mathrm{~J} / \mathrm{g})$ & $X_{c}^{d}(\%)$ \\
\hline 1 & allyl-Me-Fe & 6.04 & 10 & 5.4 & 37.7 & $85.5,127.5$ & $31.6,112.6$ & 73.4 \\
\hline 2 & & & 30 & 13.3 & 4.9 & 95.6 & 184.2 & 68.3 \\
\hline 3 & & & 50 & 21.3 & 7.7 & $72.2,131.2$ & $5.9,142.3$ & 54.9 \\
\hline 4 & allyl-Me-Co & 6.04 & 10 & 34.2 & $<2.0$ & 131.4 & 221.8 & 82.2 \\
\hline 5 & & & 30 & 52.7 & $<2.0$ & 127.3 & 217.8 & 80.7 \\
\hline 6 & & & 50 & 57.1 & $<2.0$ & 131.9 & 208.1 & 77.1 \\
\hline 7 & allyl-iPr-Fe & 6.04 & 10 & 27.9 & 175.0 & 134.1 & 150.2 & 55.7 \\
\hline 8 & & & 30 & 21.8 & 110.0 & $90.1,134.3$ & $99.0,113.4$ & 78.7 \\
\hline $8 a^{e}$ & & & 30 & 57.2 & 79.4 & 130.2 & 196.1 & 72.7 \\
\hline 9 & & & 50 & 20.3 & 97.0 & $98.0,122.2$ & $182.6,43.9$ & 84.0 \\
\hline 10 & allyl-iPr-Co & 6.04 & 10 & 23.6 & 57.0 & 135.5 & 244.9 & 90.8 \\
\hline 11 & & & 30 & 23.0 & 26.0 & 135.2 & 243.3 & 90.2 \\
\hline 12 & & & 50 & 10.5 & 23.0 & 130.8 & 240.4 & 89.1 \\
\hline 13 & bz-iPr-Fe & 6.04 & 10 & 19.0 & 507.5 & 138.8 & 171.2 & 63.5 \\
\hline 14 & & & 30 & 7.7 & 275.0 & 134.3 & 196.0 & 72.7 \\
\hline $14 \mathrm{a}^{e}$ & & & 30 & 20.4 & 152.1 & 133.2 & 209.2 & 77.6 \\
\hline 15 & & & 50 & 5.2 & 138.4 & 127.1 & 161.9 & 60.0 \\
\hline 16 & bz-iPr-Co & 6.04 & 10 & 134.6 & 32.5 & 133.0 & 247.5 & 91.7 \\
\hline 17 & & & 30 & 40.2 & 19.5 & 135.0 & 235.2 & 87.2 \\
\hline 18 & & & 50 & 18.8 & 5.9 & 131.8 & 238.4 & 88.4 \\
\hline 19 & H-iPr-Fe & 5.02 & 10 & 141.4 & 106.7 & 132.7 & 208.2 & 77.2 \\
\hline 20 & & & 30 & 316.2 & 75.5 & 130.0 & 209.3 & 77.6 \\
\hline 21 & & & 50 & 313.9 & 63.1 & 130.1 & 221.2 & 82.0 \\
\hline 22 & H-iPr-Co & 5.02 & 10 & 186.3 & 69.5 & 133.2 & 218.2 & 80.9 \\
\hline 23 & & & 30 & 177.3 & 13.8 & 132.1 & 220.4 & 81.7 \\
\hline 24 & & & 50 & 59.4 & 12.0 & 128.7 & 223.7 & 82.9 \\
\hline
\end{tabular}

${ }^{a}$ Average rate of polymerization as g-PE/mol-Mt h bar. ${ }^{b}$ Viscosity average molecular weights measured by viscometry. ${ }^{c}$ Melting temperature $\left(T_{m}\right)$ and heat of fusion $\left(\Delta H_{f}\right)$ determined by DSC. ${ }^{d}$ Crystallinity calculated by $\left(\Delta H_{f} / \Delta H_{f}^{o}\right)$ x $100\left(\Delta H_{f}^{o}=269.9 \mathrm{~J} / \mathrm{g}\right.$ for folded-chain polyethylene $)$. ${ }^{e}$ Polymerizations in the presence of excess MAO, $\left.[\mathrm{MAO}] / \mathrm{Mt}\right]=3,000$. 
polymers than other catalysts; and (7) most of the catalysts convert ethylene to highly linear polyethylene as determined by DSC ( $T_{m}$ values $127.1 \sim 138.8^{\circ} \mathrm{C}$ and very high crystallinities larger than those commercially available from ZieglerNatta polymerization). The linearity of the polyethylene could also be confirmed using NMR spectra of the polymers, i.e., only trace amounts of branched polymer were observed.

The decreased activity of the iron and cobalt complexes containing benzyloxy and allyloxy groups on pyridine rings is related to the electron-donating character as well as the coordination capability of the benzyloxy and allyloxy substituents. The influence of substituents on the cyclopentadienyl $(\mathrm{Cp})$ rings on the activity of the metallocene catalysts and on the MW of the resulting polymers has been the object of many studies. ${ }^{6-9}$ Electronic and steric effects have been considered, but the lack of kinetic data, the different reaction conditions used by the authors that hinder an accurate comparison of the results and the difficulty of singling out the steric from electronic effects, do not allow sound conclusions to be drawn, not even about the influence on activity. Nevertheless, in general, electron releasing alkyl substituents on the $\mathrm{Cp}$ rings are reported to enhance catalytic activity, at least until steric hindrance inhibits monomer coordination. The presence of electron-donating alkyl groups on the $\mathrm{Cp}$ ligands should reduce the positive charge on the metal and consequently facilitate the formation of the active cationic species (because the $\mathrm{R}^{-}$or $\mathrm{Cl}^{-}$donor strength of the metal is increased) and should also promote stabilization. ${ }^{14-16}$ However, it is expected that too strong electron-donating substituents such as benzyloxy and allyloxy groups lead to reduced electrophillic metal center, resulting in a decreased coordination power with respect to ethylene monomer, thus cause a lower propagation rate. Furthermore, the decreased activity of the iron and cobalt complexes containing benzyloxy and allyloxy groups is also caused by complicated complexations between cationic active species and benzyloxy and allyloxy groups as illustrated in Figure 2. These complexations stabilize the active species and retard the coordination of incoming monomer, resulting in decreased catalytic activity. If the polymerizations were performed in the presence of large excess amount of MAO, the MAO might protect metal center from deactivation by coordination via oxygen in allyloxy or benzyloxy groups. This was the case as shown in Table I (see run no. 8a and 14a). When [MAO]/ [Mt] ratio is 3,000 , the activity was increased by over two folds.

The prolonged induction periods observed in allyl-iPr-Fe and bz-iPr-Fe catalysts can be rationalized by above explanation. Even if it needs a long time (13 $\mathrm{min})$ to activate $\mathbf{b z}$ $\boldsymbol{i P r}$-Fe catalyst, exceptional high molecular weights of resulting polyethylenes demonstrate that the active centers are alive for a long time without chain transfer reactions. Since we realized that the substituents on the pyridine ring

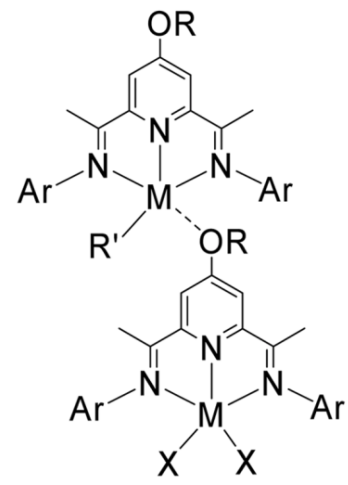

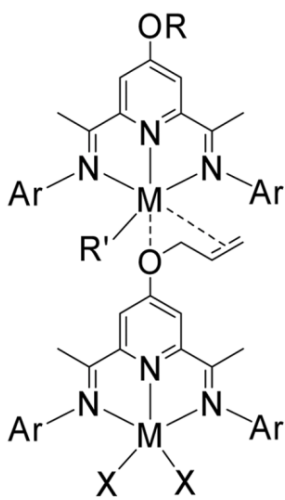

$\mathrm{R}=$ benzyl or allyl; $\mathrm{R}^{\prime}=$ alkyl; $\mathrm{M}=\mathrm{Fe}$ or $\mathrm{Co}$; $\mathrm{Ar}=2,6$-disubstituted aryl; $\mathrm{X}=$ alkyl or $\mathrm{Cl}$

Figure 2. Plausible complexations between cationic active species and benzyloxy or allyloxy groups.

are an important parameter influencing polymerization behaviors, we are carrying out similar study by modifying the substituents on the pyridine ring with electron-withdrawing group.

As a means of explaining multiple melting peaks (Table I) observed in allyl-Me-Fe and allyl-iPr-Fe catalysts, a series of solvent extraction of polyethylene was carried out using boiling ether, $n$-pentane, $n$-hexane and $n$-heptane as solvents. From this experiment we could extract the polyethylene samples by solvent soluble fractions and insoluble fractions, demonstrating the multiple melting behaviors were recorded because the polymer samples produced by allyl-Me-Fe and allyl-iPr-Fe catalysts contained polyethylenes with different molecular weights.

\section{Conclusions}

We have prepared new iron(II) and cobalt(II) catalysts based on tridentate pyridine bisimine ligands in which the imine moieties are bulky ortho-substituted aryl imines and the pyridine rings contain electron-donating groups such as allyloxy and benzyloxy groups. These catalysts showed lower activity of ethylene polymerizations to give linear polyethylene than corresponding catalysts containing no electron-donating substituents. The strong electron-donating substituents like benzyloxy and allyloxy groups are expected to lead reduced electrophillic metal center, decreasing coordination power of incoming monomer.

Acknowldgements. This work was supported by grant No. R01-2003-000-10020-0 from the Basic Research Program of the Korea Science \& Engineering Foundation. The authors are also grateful to the BK 21 Project, the Center for Ultramicrochemical Process Systems (ERC) and the National Research Laboratory Program. 


\section{References}

(1) G. J. P. Britovsek, V. C. Gibson, B. S. Kimberley, P. J. Maddox, S. J. McTavish, G. A. Solan, A. J. P. White, and D. J. Williams, Chem. Commun., 849 (1998).

(2) A. M. A. Bennett, World Patent Application 98/27124 (1998).

(3) B. L. Small, M. Brookhart, and A. M. A. Bennet, J. Am. Chem. Soc., 120, 4049 (1998).

(4) S. D. Ittel, L. K. Johnson, and M. Brookhart, Chem. Rev., 100, 1169 (2000) and references cited therein.

(5) B. L. Small and M. Brookhart, J. Am. Chem. Soc., 120, 7143 (1998).

(6) Examples for related work: (a) W. Kaminsky, Angew. Makromol. Chem., 223, 101 (1994); (b) F. Langhauser, J. Kerth, M. Kersting, P. Kiille, D. Lilge, and P. Miiller, Angew. Makromol. Chem., 223, 155 (1994); (c) M. L. H. Green and N. Ishihara, J. Chem. Soc., Dalton Trans., 657 (1994); (d) G. Erker and C. Mollenkopf, J. Organomet. Chem., 283, 173 (1994); (e) H. G. Ah, W. Milius, and S. J. Palackel, J. Organomet. Chem., 472, 113 (1994); (f) W. -M. Tsai and J. C. W. Chien, J. Polym. Sci.; Part A: Polym. Chem., 32, 149 (1994); (g) D. Fischer and R. Mulhaupt, Makromol. Chem. Phys., 195, 1443 (1994); (h) M. Bochmann, S. J. Lancaster, M. B. Hursthouse, and K. M. A. Malik, Organometallics, 13, 2235 (1994); (i) G. Erker, C. Mollenkopf, M. Grehl, R. Frohlich, C. Kruger, R. Noe, and M. Riedel, Organometallics, 13, 1950 (1994); (j) Z. Guo, D. C. Swenson, and R. F. Jordan, Organometallics, 13, 1424 (1994); (k) B. Rieger, G. Jany, R. Fawzi, and M.
Steimann, Organometallics, 13, 647 (1994); (1) G. Erker, M. Bendix, and R. Petrenz, Organometallics, 13, 456 (1994); (m) A. K. Rappe, W. M. Skiff, and C. J. Casewit, Chem. Rev., 100, 1435 (2000).

(7) P. C. Mohring and N. J. Coville; J. Organomet. Chem., 479, 1 (1994).

(8) W. Kaminsky, R. Engehausen, K. Zoumis, W. Spaleck, and J. Rohrmann, Makromol. Chem., 193, 1643 (1992).

(9) J. Tian and B. Huang, Makromol. Rapid Commun., 15, 923 (1994).

(10) N. Piccolrovazzi, P. Pino, G. Consiglio, A. Sironi, and M. Moret, Organometallics, 9, 3098 (1990).

(11) I. -M. Lee, W. J. Gauthier J. M. Ball, B. Iyengar, and S. Collins, Organometallics, 11, 2115 (1992).

(12) P. C. Mohring and N. J. Coville, J. Mol. Catal., 77, 41 (1992).

(13) P. C. Mohring, N. Vlachakis, N. E. Grimmer, and N. J. Coville, J. Organomet. Chem., 483159 (1994).

(14) J. A. Ewen, L. Haspeslagh, M. J. Elder, J. L. Atwood, H. Zhang, and H. N. Cheng, in Transition Metals and Organometallics as Catalysts for Olefin Polymerization, W. Kaminsky and H. Sinn, Eds., Springer, Berlin, 1988, pp 281-289.

(15) J. C. W. Chien and A. Razavi, J. Polym. Sci.; Part A: Polym. Chem., 26, 2369 (1988).

(16) T. Mise, S. Miya, and H. Yamazaki, Chem. Lett., 1853 (1989).

(17) I. Kim, B. H. Han, J. G. Kim, H. S. Suh, and C. -S. Ha, Macromolecules, 36, 6689 (2003).

(18) R. Chang, J. Polym. Sci., 8, 35 (1957). 